\title{
Электрические свойства гетероструктур $p$-NiO/n-Si на основе наноструктурированного кремния
}

\author{
(С) Г.П. Пархоменко, М.Н. Солован, П.Д. Марьянчук \\ Черновицкий национальный университет им. Юрия Федьковича, \\ 58012 Черновцы, Украина \\ E-mail: h.parkhomenko@chnu.edu.ua
}

(Получена 11 апреля 2017 г. Принята к печати 15 мая 2017 г.)

\begin{abstract}
Методом химического травления сформированы кремниевые нанопроволоки на подложках $n$-Si. Изготовлены гетероструктуры $p$ - $\mathrm{NiO} / n$-Si методом реактивного магнетронного напыления. Построена энергетическая диаграмма исследуемых анизотипных гетероструктур $p$ - $\mathrm{NiO} / n-\mathrm{Si}$ в соответствии с моделью Андерсона. Измерены и проанализированы вольт-амперные и вольт-фарадные характеристики. Установлены основные механизмы токопереноса через гетеропереход $p$ - $\mathrm{NiO} / n-\mathrm{Si}$ при прямых и обратных смещениях.
\end{abstract}

DOI: 10.21883/FTP.2018.07.46041.8609

\section{1. Введение}

Фотоэлектрические преобразователи солнечной энергии являются перспективной заменой ископаемым источникам энергии. Однако, несмотря на стремительное развитие и ряд своих преимуществ, технология их изготовления является затратной и они в полной мере не могут конкурировать с традиционными видами энергии. Поэтому идет интенсивный поиск методов совершенствования фотоэлектрических преобразователей солнечной энергии.

Кремний является наиболее важным полупроводниковым материалом в микроэлектронике. Солнечные элементы на основе кремния играют доминирующую роль на рынке фотоэлектрических преобразователей. Однако эффективность таких солнечных элементов достигла своего максимума. Одним из способов повышения эффективности фотоэлектрических преобразователей является модификация их наноструктурами.

Нанопроволоки на основе кремния нашли свое применение в различных приборах наноэлектроники, оптоэлектроники, сенсорики и фотовольтаики [1-7]. Существует много методов создания кремниевых нанопроволок: химическое осаждение из газовой фазы, реактивное ионное травление, химическое травление [8-12]. Последний метод представляет собой довольно простой и дешевый метод получения кремниевых нанопроволок, a также он позволяет получать нанопроволоки как на объемных кристаллах, так и на тонких пленках.

Интерес к пленкам оксида никеля (NiO) растет благодаря возможности их применения в полупроводниковых приборах. Оксид никеля широко используют в качестве антиферромагнитного слоя, электродов для электрохромных устройств, прозрачных проводящих слоев, газовых сенсоров [13-15]. Оксид никеля является широкозонным полупроводниковым материалом, с шириной запрещенной зоны 3.5-4.0 эВ, и имеет при этом $p$-тип проводимости [15]. Для получения тонких пленок $\mathrm{NiO}$ используют различные методы: спрей-пиролиз, электронно-лучевое испарение, химическое осаждение, реактивное магнетронное напыление [16-19].
Целью данной работы было создание гетероструктур на основе ноноструктурированого $n$-Si и тонких пленок $\mathrm{NiO}$, а также исследование их электрических и фотоэлектрических свойств, установление доминирующих механизмов токопереноса при прямом и обратном смещениях.

\section{2. Экспериментальная часть}

Для создания гетеропереходов использовались подложки монокристаллического кремния $n$-типа проводимости. Значение удельной электропроводности и концентрации носителей заряда базового материала при комнатной температуре $(T=295 \mathrm{~K})$ составили $\sigma=1 \mathrm{OM}^{-1} \cdot \mathrm{cm}^{-1}$ и $n=4.7 \cdot 10^{15} \mathrm{~cm}^{-3} \quad$ соответственно. Глубина залегания уровня Ферми относительно зоны проводимости $E_{c}$ для базового материала $\left(E_{c}-E_{\mathrm{F}}=0.22\right.$ эВ $)$ определялась из выражения для концентрации равновесных электронов: $n=2\left(2 \pi m_{n} k T / h^{2}\right)^{3 / 2} \exp \left[-\left(E_{c}-E_{\mathrm{F}}\right) / k T\right]$, где $m_{n}-$ эффективная масса электронов, $k-$ постоянная Больцмана. На подложках выращивались нанопроволоки с помощью травления при участии наночастиц серебра. Перед выращиванием нанопроволок кремниевые подложки протравливались в растворе серной кислоты и $30 \%$-й перекиси водорода $\left(\mathrm{H}_{2} \mathrm{O}_{2}\right)$ в соотношении $(3: 1)$ для удаления органических загрязнений. После очистки кремниевые образцы погружались в водные растворы $0.02 \mathrm{M} \mathrm{AgNO}_{3}$ и $5 \mathrm{M}$ плавиковой кислоты $(\mathrm{HF})$ в соотношении $(1: 1)$ на 5-10 с для того, чтобы наночастицы серебра осели на подложки. Следующим шагом было травление кремниевых подложек с наночастицами серебра в растворе $5 \mathrm{M}$ HF и $30 \%$-й $\mathrm{H}_{2} \mathrm{O}_{2}$ в соотношении $(10: 1)$ для создания нанопроволок. Последний этап это вытравливание наночастиц серебра с подложки с помощью азотной кислоты.

Нанесение пленок $\mathrm{NiO}$ проводилось на наноструктурированные подложки монокристаллического $\mathrm{Si}$ (размером $5 \times 5 \times 1$ мм) в универсальной вакуумной уста- 
новке Leybold-Heraeus L560 с помощью реактивного магнетронного распыления мишени из чистого никеля в атмосфере смеси аргона и кислорода при постоянном напряжении.

Подложки размещались над магнетроном с последующим вращением столика для обеспечения однородности пленок по толщине. Перед началом процесса напыления вакуумная камера откачивалась до остаточного давления $5 \cdot 10^{-5}$ мбар.

Для напыления пленок $\mathrm{NiO}$ никелевая мишень (99.99) (шайба диаметром 100 мм и толщиной 1 мм) размещалась на столике магнетрона с водяным охлаждением на расстоянии 7 см от подложек. Использовалось кратковременное протравливание бомбардирующими ионами аргона поверхности мишени и подложки для удаления неконтролируемого загрязнения.

В течение процесса напыления парциальные давления в вакуумной камере составляли $\sim 4 \cdot 10^{-3}$ мбар для аргона и $\sim 4 \cdot 10^{-3}$ мбар для кислорода. Установленная мощность магнетрона составляла $\sim 100$ Вт. Процесс напыления длился $\sim 10$ мин при температуре подложек $\sim 373 \mathrm{~K}$.

Напыленные пленки оксида никеля имели $p$-тип проводимости, а концентрация носителей заряда и электрическая проводимость при $T=295 \mathrm{~K}$ составляли $p=4.2 \cdot 10^{19} \mathrm{~cm}^{-3}$ и $\sigma=0.56 \mathrm{OM}^{-1} \cdot \mathrm{cm}^{-1}$ соответственно.

Фронтальный электрический контакт к тонкой пленке $\mathrm{NiO}$ формировался с помощью реактивного магнетронного распыления никеля при температуре подложки $373 \mathrm{~K}$.

Омические контакты к $n$-Si были получены с помощью предварительного легирования фосфором тыльной поверхности подложки, что приводит к образованию $n^{+}$-области. После обработки на поверхность последовательно наносили слои хрома и никеля путем термического испарения.

Измерения вольт-фарадных характеристик гетероструктуры проводились с помощью LCR Meter BR2876. Вольт-амперные характеристики исследуемых гетероструктур измеряли по стандартной методике с использованием точного фемто/пико амперметра Keysight В2985A со встроенным источником $( \pm 1000 \mathrm{~B})$, а в качестве вольтметра использовали Agilent 34410A.

\section{3. Результаты и их обсуждение}

На рис. 1 приведена энергетическая диаграмма исследуемых анизотипных гетероструктур $p-\mathrm{NiO} / n-\mathrm{Si}$, которая была построена на основе данных, взятых из литературных источников [20-25], без учета поверхностных состояний на границе раздела. Положение уровня Ферми для $\mathrm{Si}$ и $\mathrm{NiO}$ определялось на основе экспериментально полученных значений концентрации носителей заряда в Si и $\mathrm{NiO}$.

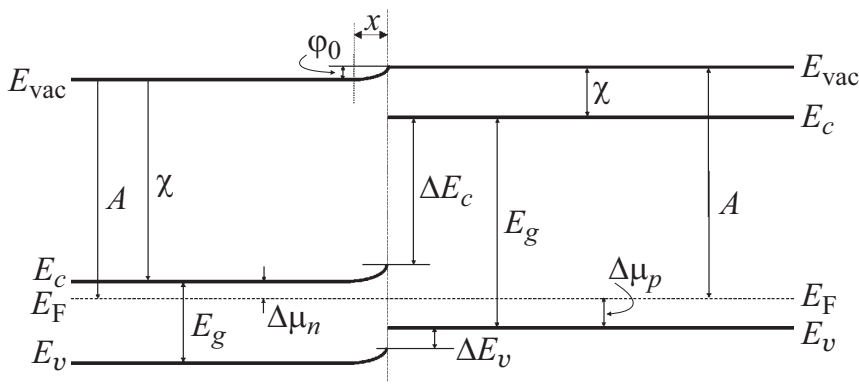

Рис. 1. Энергетическая диаграмма анизотипной гетероструктуры $p-\mathrm{NiO} / n-\mathrm{Si}\left(E_{\mathrm{vac}}-\right.$ уровень вакуума, $E_{c}, E_{x}-$ края зон проводимости и валентной, $E_{g}$ - ширина запрещенной зоны, $\chi-$ сродство к электрону, $A-$ работа выхода). NiO: $E_{g}=3.9$ эB, $\chi=1.45$ эB, $A=4.9{ }_{\ni} \mathrm{B}, \Delta \mu_{p} \approx 0.34$ эВ. Si: $E_{g}=1.12$ эВ, $\chi=4.05$ эВ, $A=4.8$ эВ $\Delta \mu_{n}=0.22$ эВ. Разрывы зон: $\Delta E_{c}=2.6$ эВ, $\Delta E_{v}=0.18$ эВ. Высота барьера $\varphi_{0}=0.1$ эВ.

Разрыв зон проводимости $\Delta E_{c}$ значительно превышает разрыв валентных зон $\Delta E_{v}$. Поэтому можно утверждать, что электрический ток через исследуемый гетеропереход будет формироваться носителями заряда одного типа - дырками.

Для расчета толщины обедненных областей в $\mathrm{Si}$ и $\mathrm{NiO}$ можно использовать следующие выражения [20,26]:

$$
\begin{gathered}
x_{n}=\sqrt{\frac{2 \varepsilon_{0} N_{A} \varepsilon_{n} \varepsilon_{p} \varphi_{0}}{e N_{D}\left(\varepsilon_{n} N_{D}+\varepsilon_{p} N_{A}\right)}}, \\
x_{p}=\sqrt{\frac{2 \varepsilon_{0} N_{D} \varepsilon_{n} \varepsilon_{p} \varphi_{0}}{e N_{A}\left(\varepsilon_{n} N_{D}+\varepsilon_{p} N_{A}\right)}},
\end{gathered}
$$

где $e-$ заряд электрона, $\varepsilon_{0}-$ электрическая постоянная $\left(8.85 \cdot 10^{-12} \Phi \cdot \mathrm{M}^{-1}\right), \varepsilon_{p}$ и $N_{A}-$ относительная диэлектрическая проницаемость и концентрация акцепторов в $\mathrm{NiO}, \varepsilon_{n}$ и $N_{D}-$ относительная диэлектрическая проницаемость и концентрация доноров в $\mathrm{Si}, \varphi_{0}-$ высота потенциального барьера.

Полученные значения $x_{p}$ и $x_{n}$ составляют $3.1 \cdot 10^{-11}$ и $2.6 \cdot 10^{-6}$ м соответственно. Поскольку $x_{n} \gg x_{p}$, можно считать, что область пространственного заряда гетероструктуры $p$ - $\mathrm{NiO} / n-\mathrm{Si}$ полностью формируется в $\mathrm{Si}$ $\left(x_{n}=x\right)$.

На рис. 2 изображены вольт-фарадные характеристики $C(V)$ исследуемого гетероперехода с учетом последовательного сопротивления $R_{s}$, измеренные при $297 \mathrm{~K}$, постоянной амплитуде $10 \mathrm{MB}$ и различных частотах возбуждающего сигнала. Линейность вольт-фарадных характеристик гетероперехода $p-\mathrm{NiO} / n-\mathrm{Si}$ в координатах $C^{-2}$ от $\left(V-I R_{s}\right)$, где $V-$ приложенное к гетероструктуре напряжение, $I-$ ток через структуру при соответствующем значении $V$, свидетельствует о равномерном распределении нескомпенсированной примеси в пределах области пространственного заряда [27].

Частотная зависимость наклона вольт-фарадных характеристик свидетельствует о наличии электрически 


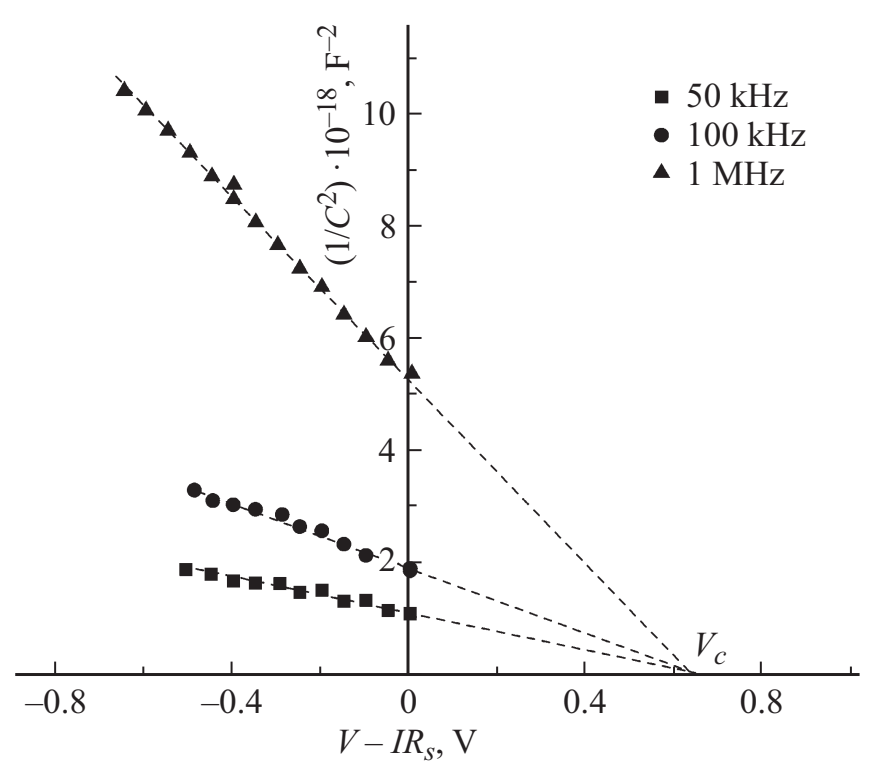

Рис. 2. Вольт-фарадные характеристики гетероперехода $p-\mathrm{NiO} / n-\mathrm{Si}$ при $295 \mathrm{~K}$.

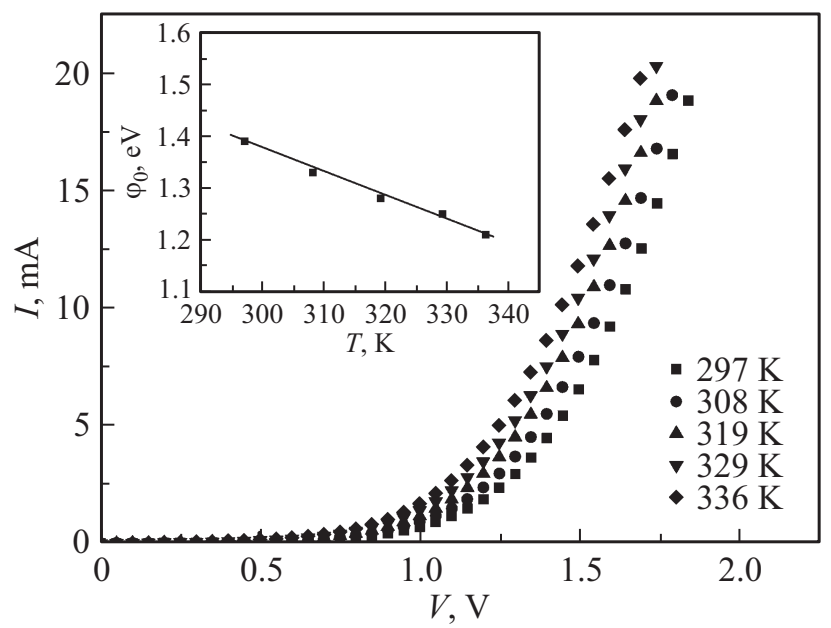

Рис. 3. Вольт-амперные характеристики гетероперехода $p$-NiO/n-Si. На вставке - температурная зависимость высоты потенциального барьера.

активных поверхностных ловушек на границе раздела исследуемого гетероперехода с разным характеристическим временем перезарядки. Величина напряжения отсечки определена из вольт-фарадных характеристик $\left(V_{c}=0.64 \mathrm{~B}\right)$, и она почти не зависит от частоты возбуждающего сигнала (рис. 2). Величина напряжения отсечки, определенная из вольт-фарадных характеристик, меньше значения встроенного потенциала, определенного из вольт-амперной характеристики $I(V)$ (рис. 3) при той же температуре. Это обстоятельство хорошо объясняется в рамках модели, предложенной в [28], которая учитывает наличие электрического заряда, локализованного на поверхностных состояниях на металлургической границе раздела гетероперехода:

$$
V_{c}=V_{b i}-\frac{Q_{s s}^{2}}{2 e \varepsilon_{0}\left(\varepsilon_{p} N_{A}+\varepsilon_{p} N_{D}\right)},
$$

где $Q_{s s}=e N_{s s}$ - электрический заряд, накопленный на единице площади границы раздела гетероперехода, $V_{b i}$ - величина строенного потенциала. Рассчитанное значение поверхностной плотности электрически активных состояний на основе формулы (3) составляет $N_{s s} \approx 2.1 \cdot 10^{13} \mathrm{~cm}^{-2}$.

При такой плотности поверхностные состояния могут играть роль центров захвата или рекомбинации и существенно влиять на электрические свойства гетероструктур $[26,29]$.

На рис. 3 представлены прямые ветви вольт-амперных характеристик (BAX) гетероструктур при различных температурах. Температурная зависимость высоты потенциального барьера (см. вставку на рис. 3) хорошо описывается уравнением $\varphi_{0}(T)=\varphi_{0}(0)-\beta_{\varphi} T$, где $\beta_{\varphi}=4.68 \cdot 10^{-3}$ эВ $\cdot \mathrm{K}^{-1}$ - температурный коэффициент высоты потенциального барьера, а $\varphi_{0}(0)=2.78$ эВ значение высоты потенциального барьера исследуемой гетероструктуры при абсолютном нуле температуры.

Величина последовательного сопротивления гетероструктур была определена из наклона вольт-амперных характеристик и составила $R_{s}=24$ Ом. Отсутствие температурной зависимости последовательного сопротивления свидетельствует об истощении донорного уровня базового материала в исследуемом интервале температур [25].

Для установления доминирующих механизмов токопереноса в гетеропереходе $p$ - $\mathrm{NiO} / n-\mathrm{Si}$ прямые ветви вольт-амперных характеристик были построены в полулогарифмических координатах. Видно, что ВАХ аппроксимируются прямыми линиями, что указывает на экспоненциальную зависимость тока от напряжения. Большое значение коэффициента неидеальности $n \approx 7$, определенного из $\Delta \ln I / \Delta V \propto e / n k T$, и постоянный наклон ВАХ при различных температурах указывают на доминирование туннельного механизма токопереноса (рис. 4), при котором BAX описывается формулой $I=I_{0} \exp (\alpha V)$, где $I_{0}=I_{t}^{0} \exp (\gamma T)-$ ток отсечки, $\alpha, \gamma$ - константы. Экспериментальное значение $\alpha=4.7$ было определено из зависимости $\ln I=f(V)$. Экстраполяцией прямолинейных участков до пересечения с осью ординат было определено значение $\ln I_{0}$. Температурная зависимость логарифма туннельного тока $\ln I_{0}$ при $V=0$ имеет линейный характер (см. вставку на рис. 4), что позволяет определить коэффициенты: $I_{t}^{0}=9.17 \cdot 10^{-9} \mathrm{~A}$, $\gamma=1.97 \cdot 10^{-3} \mathrm{~K}^{-1}$.

При обратном смещении в области напряжений $3 k T<|V|<0.65$ В аппроксимация ВАХ прямыми в координатах $\ln I_{\text {rev }}=f\left(\varphi_{0}-e V\right)^{-1 / 2}$ (рис. 5) подтверждает доминирование туннельного механизма токопереноса. ВАХ в этом случае описывается вы- 


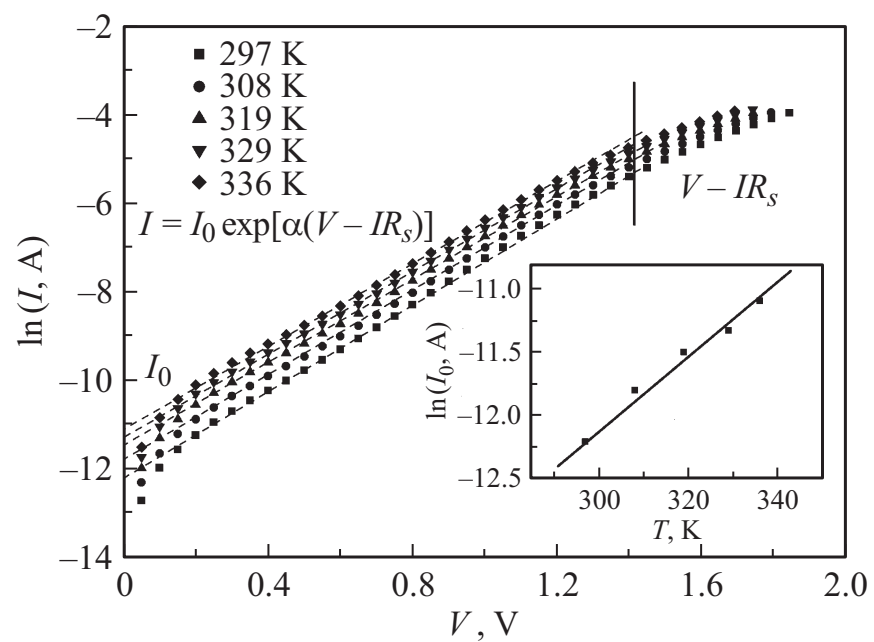

Рис. 4. Прямые ветви вольт-амперных характеристик гетероструктуры $p-\mathrm{NiO} / n-\mathrm{Si}$ в полулогарифмическом масштабе. На вставке - температурная зависимость тока отсечки.

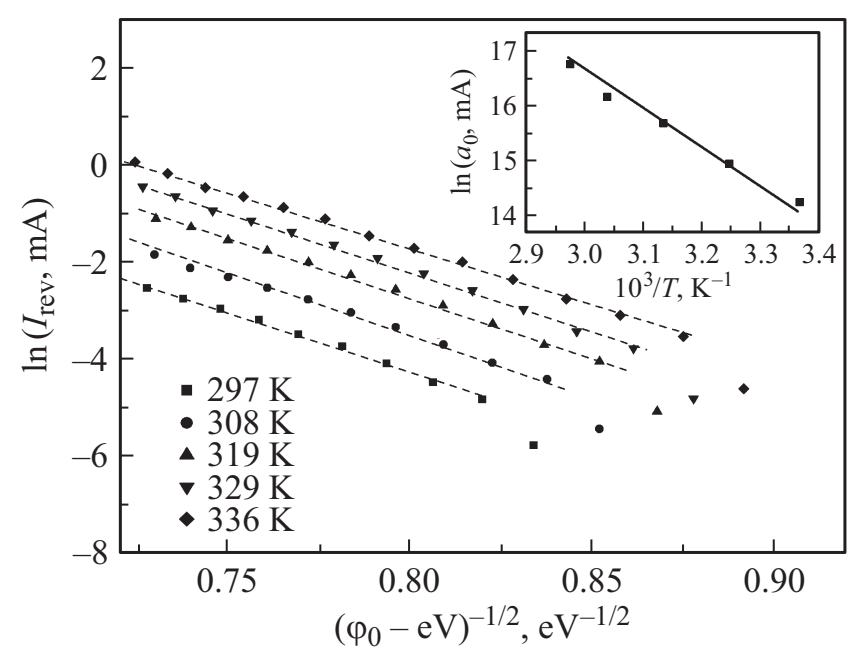

Рис. 5. Обратные ветви вольт-амперных характеристик гетероструктуры $p-\mathrm{NiO} / n$-Si в координатах $\ln I_{\text {rev }}=f\left(\varphi_{0}-e V\right)^{-1 / 2}$ $(3 k T<|V|<0.65 \mathrm{~B})$. На вставке - температурная зависимость параметра $a_{0}$.

ражением $[21,26]$

$$
I_{\mathrm{rev}} \approx a_{0} \exp \left(\frac{b_{0}}{\sqrt{\varphi_{0}(T)-e V}}\right),
$$

где $a_{0}-$ параметр, определяющийся вероятностью заполнения энергетических уровней, с которых происходит туннелирование, $b_{0}$ определяет скорость изменения тока с напряжением. Из наклона температурной зависимости $\ln a_{0}=f\left(10^{3} / T\right)$ можно определить глубину залегания энергетического уровня [26,30], которая составляет 0.14 эВ (см. вставку на рис. 5).

В области напряжений $|V|>0.65 \mathrm{~B}$ механизмы токопереноса хорошо описываются моделью Френкеля-Пула. Для данного случая обратные ветви ВАХ описываются выражением [25,31]

$$
\left.I_{\text {rev }} \propto|V| \exp \beta \sqrt{|V| / T}\right]
$$

где $\beta$ - постоянная. Линейная зависимость обратного тока от напряжения в координатах $\ln I_{\text {rev }}=f\left(|V|^{1 / 2}\right)$ свидетельствует о преобладании данного механизма токопереноса (рис. 6).

Спектральное распределение квантовой эффективности $\eta$ исследуемых гетеропереходов определяется как отношение количества носителей заряда, формирующих ток короткого замыкания, к числу падающих фотонов при освещении гетероперехода со стороны пленки $\mathrm{NiO}$ за единицу времени и характеризуется шириной полосы на половине его высоты $\delta_{1 / 2} \approx 0.62$ мкм (рис. 7).

Энергетическое положение длинноволнового края спектра квантовой эффективности хорошо согласуется с шириной запрещенной зоны $\mathrm{Si}$. Коротковолновой край

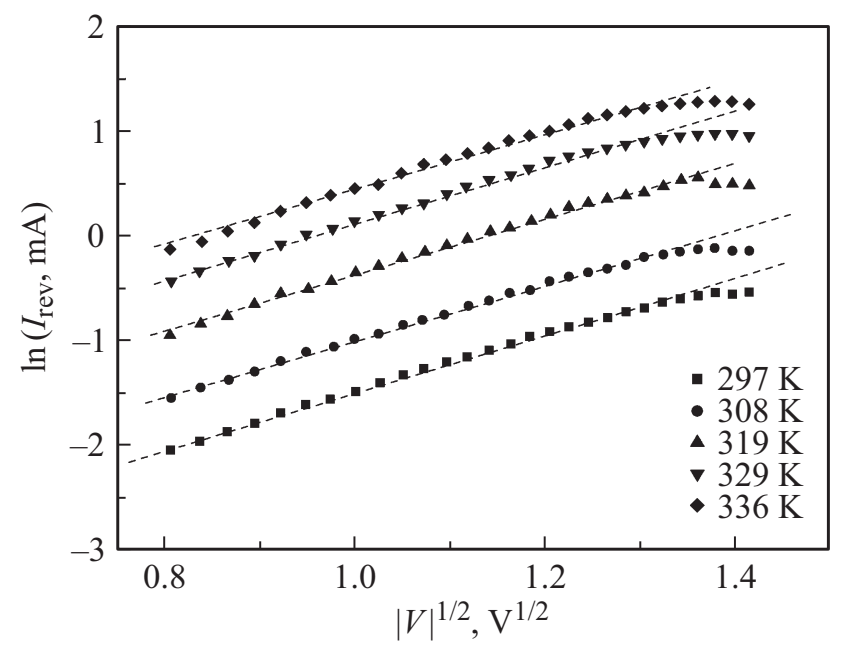

Рис. 6. Обратные ветви вольт-амперных характеристик гетероструктуры $p$-NiO/n-Si в координатах $\ln I_{\text {rev }}=f\left(|V|^{1 / 2}\right)$ $(|V|>0.65 \mathrm{~B})$.

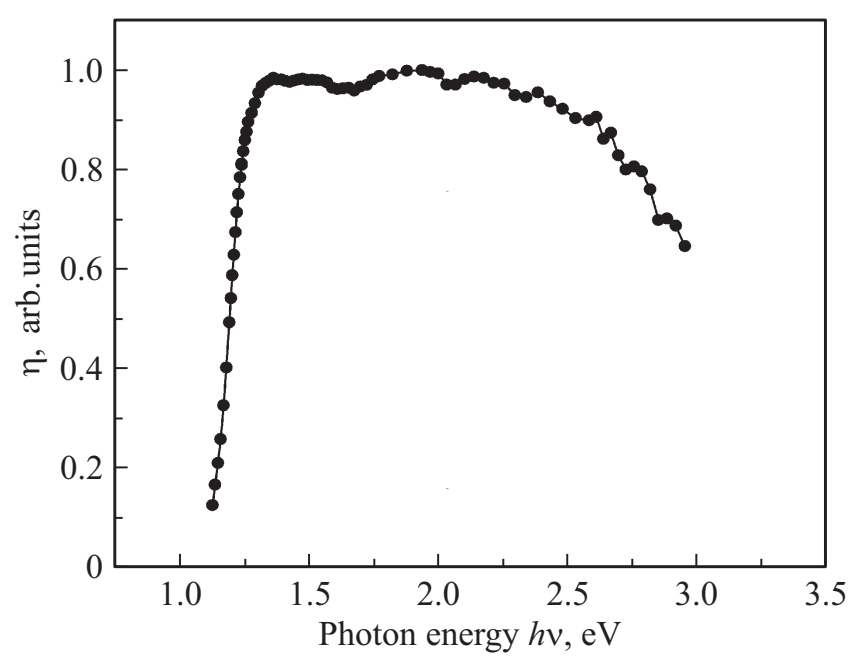

Рис. 7. Спектральное распределение действительной квантовой эффективности гетероперехода $p-\mathrm{NiO} / n-\mathrm{Si}$. 
спектральной фоточувствительности хорошо согласуется с шириной запрещенной зоны $\mathrm{NiO}$. Отсутствие резкого коротковолнового края в спектрах квантовой эффективности связано с малой толщиной пленки $\mathrm{NiO}$ и ее поликристаллической структурой.

\section{4. Заключение}

Сформированы кремниевые нанопроволоки на подложках $n$-Si методом химического травления. Изготовлены гетероструктуры $p$ - $\mathrm{NiO} / n-\mathrm{Si}$ путем осаждения тонких пленок $\mathrm{NiO}$ методом реактивного магнетронного напыления.

Построена энергетическая диаграмма исследуемых анизотипных гетероструктур $p$ - $\mathrm{NiO} / n-\mathrm{Si}$ в соответствии с моделью Андерсона, без учета поверхностных электрических состояний. Проведены исследования электрических свойств гетеропереходов $p-\mathrm{NiO} / n-\mathrm{Si}$ в интервале температур 297-336 K.

Установлено, что электрический ток через исследуемую гетероструктуру при прямом смещении обусловлен туннелированием через область пространственного заряда. При обратном смещении в области напряжений $3 k T<|V|<0.65$ В сновным механизмом токопереноса является туннелирование через область пространственного заряда, а в области напряжений $|V|>0.65 \mathrm{~B}$ механизмы токопереноса хорошо описываются моделью Френкеля-Пула.

Исследовано и проанализировано спектральное распределение квантовой эффективности $\eta$ гетеропереходов.

\section{Список литературы}

[1] B. Hoffmann, J. Jiruse, J. Dluhoš, M. Latzel, M.Y. Bashouti, S.M. Schmitt, S. Christiansen, V. Sivakov. Wet-Chemically Etched Silicon Nanowire Solar Cells: Fabrication and Advanced Characterization. INTECH Open Access Publisher (2012).

[2] V. Schmidt, J.V. Wittemann, S. Senz, U. Gösele. Adv. Mater., 21 (25-26), 2681 (2009).

[3] C.K. Chan, H. Peng, G. Liu, K. McIlwrath, X.F. Zhang, R.A. Huggins, Y. Cui. Nature Nanotechnol., 3 (1), 31 (2008).

[4] A.I. Boukai, Y. Bunimovich, J. Tahir-Kheli, J.K. Yu, W.A. Goddard Iii, J.R. Heath. Nature, 451 (7175), 168 (2008).

[5] R. He, P. Yang. Nature Nanotechnol., 1 (1), 42 (2006).

[6] X.T. Zhou, J.Q. Hu, C.P. Li, D.D.D. Ma, C.S. Lee, S.T. Lee. Chem. Phys. Lett., 369 (1), 220 (2003).

[7] S.W. Chung, J.Y. Yu, J.R. Heath. Appl. Phys. Lett., 76 (15), 2068 (2000).

[8] J. Westwater, D.P. Gosain, S. Tomiya, S. Usui, H. Ruda. J. Vac. Sci. Technol. B, 15 (3), 554 (1997).

[9] Y.F. Zhang, Y.H. Tang, N. Wang, D.P. Yu, C.S. Lee, I. Bello, S.T. Lee. Appl. Phys. Lett., 72 (15), 1835 (1998).

[10] J.Y. Yu, S.W. Chung, J.R. Heath. J. Phys. Chem. B, 104 (50), 11864 (2000).

[11] C. Chartier, S. Bastide, C. Lévy-Clément. Electrochim. Acta, 53 (17), 5509 (2008).

[12] Z. Huang, N. Geyer, P. Werner, J. De Boor, U. Gösele. Adv. Mater., 23 (2), 285 (2011).
[13] J.A. Dirksen, K. Duval, T.A. Ring. Sensors Actuators B: Chemical, 80 (2), 106 (2001).

[14] H.P. Parkhomenko, M.N. Solovan, A.I. Mostovyi, K.S. Ulyanytsky, P.D. Maryanchuk. Semiconductors, 51 (3), 344 (2017).

[15] H. Sato, T. Minami, S. Takata, T. Yamada. Thin Sol. Films, 236(1-2), 27 (1993).

[16] P.S. Patil, L.D. Kadam. Appl. Surf. Sci., 199 (1), 211 (2002).

[17] R.C. Korošec, P. Bukovec. Acta Chim. Slovaca, 53, 136 (2006).

[18] J. Tamaki, C. Naruo, Y. Yamamoto, M. Matsuoka. Sensors Actuators B: Chemical, 83 (1), 190 (2002).

[19] D.Y. Jiang, J.M. Qin, X. Wang, S. Gao, Q.C. Liang, J.X. Zhao. Vacuum, 86 (8), 1083 (2012).

[20] А. Фаренбрух, Р. Бьюб. Солнечные элементы: теория и эксперимент (М., Энергоатомиздат, 1987) [Пер. с англ.: A.L. Fahrenbruch, R.H. Bube. Fundamentals of solar cells. Photovoltaic solar energy conversion (N.Y., 1983)].

[21] Б.Л. Шарма, Р.К. Пурохит. Полупроводниковые гетеропеpeходы (М., Сов. радио, 1979) [Пер. с англ.: B.L. Sharma, R.K. Purohit. Semiconductor heterojunctions (Pergamon Press, 1974)].

[22] Физико-химические свойства окислов, под. ред. Г.В. Самсонова (М., Металлургия, 1978).

[23] S.C. Choi, K. Koumoto, H. Yanagida. J. Mater. Sci., 21 (6), 1947 (1986).

[24] T.M. Ramond, G.E. Davico, F. Hellberg, F. Svedberg, P. Salén, P. Söderqvist, W.C. Lineberger. J. Molecular Spectroscopy, 216 (1), 1 (2002).

[25] M.N. Solovan, V.V. Brus, P.D. Maryanchuk. Semiconductors, $48(2), 219$ (2014).

[26] M.N. Solovan, V.V. Brus, P.D. Maryanchuk. Semiconductors, 48 (7), 899 (2014).

[27] Л.С. Берман. Емкостные методы исследования полупроводниковых приборов (Л., Наука, 1972).

[28] J.P. Donnelly, A.G. Milnes. IEEE Trans. Electron Dev., 14 (2), 63 (1967).

[29] V.V. Brus. Semicond. Sci. Technol., 28 (2), 025013 (2013).

[30] M.M. Solovan, V.V. Brus, P.D. Maryanchuk. Semiconductors, 47 (9), 1174 (2013).

[31] S.M. Sze, K. Kwok. Physics of Semiconductor Devices, 3rd edn (New Jersey, Wiley, 2007).

Редактор Л.В. Шаронова

\section{Electrical properties of $p-\mathrm{NiO} / n-\mathrm{Si}$ heterostructures based on nanostructured silicon}

\section{H.P. Parkhomenko, M.N. Solovan, P.D. Maryanchuk}

Yuriy Fedkovych Chernivtsi National University, 58012 Chernivtsi, Ukraine

Abstract Silicon nanowires were formed on $n$-Si substrates by chemical etching method. Heterojunctions $p-\mathrm{NiO} / n-\mathrm{Si}$ were fabricated by reactive magnetron sputtering. The energy diagram of the anisotype investigated heterostructures $p-\mathrm{NiO} / n-\mathrm{Si}$ was built in accordance with the Anderson model. The currentvoltage and capacitance-voltage characteristics were measured and analyzed. The basic mechanisms of charge transport through the heterojunction $p-\mathrm{NiO} / n-\mathrm{Si}$ at forward and reverse bias were established. 